Revista Destaques Acadêmicos, Lajeado, v. 10, n. 1, 2018. ISSN 2176-3070

DOI: http://dx.doi.org/10.22410/issn.2176-3070.v10i1a2018.1778

http://www.univates.br/revistas

\title{
TÉCNICAS DE VISUALIZAÇÃO DE INFORMAÇÕES COMO APOIO À GESTÃO ESTRATÉGICA
}

\author{
Rodrigo Pinheiro de Oliveira ${ }^{1}$, Maria Claudete Schorr Wildner², \\ Fabrício Pretto ${ }^{3}$
}

\begin{abstract}
Resumo: A área de visualização de informação tem como objetivo auxiliar no processo de apresentação de dados, por meio de suas técnicas pode-se interpretar e entender melhor as informações, combinando aspectos de visualização científica, mineração de dados, interfaces homem-computador, computação gráfica e processamento de imagens. O objetivo do presente trabalho é identificar formas de visualização alternativas para informações gerenciais, oferecendo maior qualidade durante o processo de análise das informações. Para isso, desenvolveu-se um protótipo na plataforma web, para apresentação de dados de forma gráfica, tornando possível a comparação entre diferentes modelos de gráficos para análise da mesma informação. Após a implementação foi feita uma pesquisa com uma amostra de 11 usuários, com perfil administrativo, os quais estão acostumados a realizar análises gerenciais e interpretar gráficos. Durante os testes foram avaliadas características como clareza, facilidade de interpretação e esforço cognitivo para compreensão dos dados. Dentre as opções de visualização propostas, buscou-se entender quais modelos geram mais informações em uma única visualização, comparando as formas tradicionais (gráficos de pizza ou barras) com modelos de visualização mais elaborados.
\end{abstract}

Palavras-chave: Visualização de informações. Dados. Técnicas de visualização. Informação gerencial.

\section{INTRODUÇÃO}

O avanço das tecnologias torna os sistemas computacionais cada vez mais robustos e com maior capacidade de processamento de dados. A

1 Universidade do Vale do Taquari - Univates.

2 Universidade do Vale do Taquari - Univates.

3 Mestre em Ciência da Computação. Professor na Universidade do Vale do Taquari - Univates. Atuante nos cursos de Sistemas de Informação, Engenharia de Software e Engenharia da Computação. Atuação na extensão como voluntário e coordenador do projeto Competição de Robótica 
área de visualização de informações utilizando-se de representações visuais proporciona uma forma mais simples e intuitiva no processo de interpretação de dados, conforme Vaz e Carvalho (2004) uma maneira de realizar esta interpretação, é utilizar-se das técnicas de visualização de informação, onde é possível reunir um número maior de informações em apenas uma imagem, sendo possível também descobrir padrões eventualmente ocultos, auxiliando no entendimento e disponibilizando diferentes formas de representação da mesma informação.

O método de visualização origina-se do sentido humano com maior capacidade de obtenção de informação, a visão. Através da construção de representações visuais, por exemplo, é possível identificar padrões, formas e cores distintas, facilitando a localização de objetos específicos em uma imagem (NASCIMENTO; FERREIRA, 2011).

Barbosa (2010) aborda em seu trabalho a utilização de técnicas de visualização de informações para o estudo de tráfegos e gerenciamento de redes, considerando a complexidade associada às infraestruturas de redes e ao grande volume de dados gerados pelos processos de análises. $\mathrm{O}$ autor ressalta a importância dos mecanismos de interação disponibilizados aos usuários ao utilizar as técnicas de visualização de informações. Os dados apresentados em gráficos, animações ou imagens possibilitam a identificação de padrões, anomalias e interferências de maneira rápida e intuitiva. De acordo com Brum (1998) $75 \%$ do conhecimento que adquirimos vem através da visão, da forma como visualizamos e interpretamos as coisas.

A área de visualização de informações combina aspectos da visualização científica, mineração de dados, interfaces homem-computador, computação gráfica e processamento de imagens. Diferentemente dos conceitos de visualização científica, que tratam dados concretos, amostrados, medidos ou calculados de alguma forma, a área de visualização de informações trata dados que são geralmente abstratos, ou seja, informações que normalmente não são mapeadas automaticamente para o mundo físico (ESTIVALET, 2000).

Este trabalho tem como objetivo avaliar a percepção de gestores do comércio de Lajeado em relação a representação de dados em diferentes formatos de visualização, onde ao apresentar as diferentes formas de visualizar a mesma informação para os gestores buscou-se identificar qual técnica apresenta melhor resultado quanto a interpretação de informações e como estas visualizações podem auxiliar na gestão estratégica.

\section{VISUALIZAÇÃO DE INFORMAÇÕES}

Ao verificar no dicionário pela palavra visualização encontra-se a seguinte definição: "transformação de conceitos abstratos em imagens reais ou mentalmente visíveis. Conversão de números ou dados para um formato gráfico, que pode ser mais facilmente entendido" (MICHAELIS, 2018, texto 
online). Segundo Romani e Rocha (2001) a visualização, de forma geral, é o uso de imagens para representação de informações significativas, todos os tipos de visualização compartilham um objetivo em comum: transformar dados em algo mais expressivo, ou seja, uma representação visual útil de forma que o observador humano possa ter um melhor entendimento.

Segundo Freitas et al. (2001), a visualização de informações permite que os dados sejam apresentados em formas gráficas de modo que o usuário possa utilizar sua percepção visual para compreender e analisar as informações, trata dados abstratos como relacionamentos ou informações inferidas com base nos dados mensurados. As técnicas de visualização de informações visam representar graficamente dados em um determinado domínio de aplicação de modo que a representação visual gerada explore a habilidade de percepção do homem e a partir das relações espaciais exibidas ele interprete e compreenda as informações apresentadas a fim de chegar a novos conhecimentos. O objetivo é auxiliar no entendimento de determinado assunto, dado ou informação, no qual, sem uma visualização, exigiria maior esforço para sua compreensão.

\section{REPRESENTAÇÕES VISUAIS}

Todos os dias somos expostos a muitas informações, e-mails, folhetos de publicidade, notificações no smartphone chegam a todo momento, sendo que quase sempre envolvem uma tomada de decisão, qual e-mail ou correspondência podemos descartar? A fatura do cartão já foi paga? Por que recebi só agora? É comum utilizarmos representações visuais para entender estas informações, por exemplo, ao recebermos um e-mail com um itinerário de uma viagem, se for apresentado imagens juntamente a este itinerário, imaginaremos o trajeto desta viagem, e entenderemos muito mais rápido a informação apresentada. Isso é possível graças a nossa capacidade de percepção visual, que é muito mais eficaz que o texto escrito (MAZZA, 2009).

De acordo com Freitas et al. (2001) as representações visuais correspondem às imagens ou figuras utilizadas para representar o conjunto de dados sob análise. Tradicionalmente utilizamos gráficos para representar relações entre atributos, gráficos de linha, de torta, de pontos, de barras e histograma de frequência. Porém além destes modelos tradicionais existem uma série de representações gráficas que podem ser utilizadas para estabelecer relações entre entidades ou elementos de dados, representando graficamente os elementos visuais. No Quadro 1 é possível visualizar diferentes formas de representação de dados de acordo com sua classe e tipo. 
Quadro 1: Classes de representações visuais

\begin{tabular}{|l|l|l|}
\hline Classe & Tipo & Utilização \\
\hline Gráficos 2D, 3D & $\begin{array}{l}\text { Pontos, circulares, } \\
\text { linhas, barras, } \\
\text { superfícies (para 3d). }\end{array}$ & $\begin{array}{l}\text { Representação da distribuição dos } \\
\text { elementos no espaço domínio, } \\
\text { representação da dependência/correlação } \\
\text { entre atributos. }\end{array}$ \\
\hline $\begin{array}{l}\text { Ícones, glifos, } \\
\text { objetos } \\
\text { geométricos }\end{array}$ & $\begin{array}{l}\text { Elementos geométricos } \\
\text { 2D, 3D, diversos }\end{array}$ & $\begin{array}{l}\text { Representação de entidades em um } \\
\text { contexto, representação de grupos de } \\
\text { atributos de diversos tipos. }\end{array}$ \\
\hline Mapas & $\begin{array}{l}\text { De pseudo-cores, de } \\
\text { linhas, de superfícies, } \\
\text { de ícones, símbolos } \\
\text { diversos }\end{array}$ & $\begin{array}{l}\text { Representação de campos escalares, de } \\
\text { linha de contorno de regiões, isovalores, } \\
\text { espaço 3D, grupos de atributos (categorias, } \\
\text { escalares, vetoriais e tensoriais). }\end{array}$ \\
\hline Diagramas & Nodos e arestas & $\begin{array}{l}\text { Representação de relacionamentos } \\
\text { diversos: comunicação, sequência, } \\
\text { referência, entre outros. }\end{array}$ \\
\hline
\end{tabular}

Fonte: adaptado Freitas et al. (2001).

\section{MECANISMOS DE INTERAÇÃO}

De acordo com Estivalet (2000) um dos desafios relacionados a projetos de sistemas de visualização envolve a criação de interfaces flexíveis que forneçam ferramentas de navegação e métodos de pesquisa apropriados, levando em consideração os tipos de usuários existentes, devendo também apresentar uma boa interação entre homem-computador. É necessário entender como o ser humano interage com a informação, como as informações são percebidas visualmente e não-visualmente, como a mente humana resolve e compreende os dados apresentados.

$\mathrm{Na}$ maioria dos casos para obter uma avaliação eficiente de uma determinada quantidade de dados deve-se utilizar ferramentas que possibilitem o usuário explorar diferentes ações em diversos níveis de visualização, não ficando apenas em uma visualização em modo estático, ou seja, ao realizar ações que são caracterizadas pela modificação da representação visual, é possível que novas visões dos dados sejam observadas e interpretadas.

Operações que são encontradas na maioria das técnicas são de agrupamento, poda e expansão, operações estas que são fundamentais no apoio ao processo de exploração e navegação, alterando a representação com objetivo de mostrar somente a região de interesse selecionada, na qual ocupará o campo de visão principal, mantendo o restante do conjunto de dados em área a parte, sendo a região de interesse e a visão geral exibidos simultaneamente. A técnica Flip Zooming exemplifica essa situação, pois nela os dados são agrupados, 
sendo possível dar ênfase na área com maior número de informações (VAZ; CARVALHO, 2004).

\section{MODELO DE REFERÊNCIA DE VISUALIZAÇÃO}

Ao realizarmos a escolha de determinada técnica podemos identificar os componentes essenciais a serem considerados utilizando um modelo de referência de visualização. Freitas et al. (2001) sugere eu seu artigo o modelo clássico de visualização de Haber e McNabb, onde os dados passam por uma filtragem, após são mapeados e passam pelo processo de geração de imagem (rendering) gerando a representação visual. A Figura 1 representa este processo.

Figura 1: Modelo clássico de visualização de Haber e McNabb

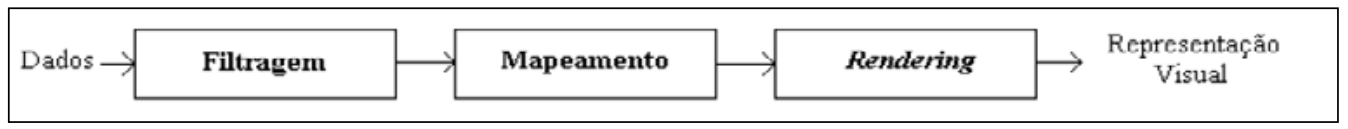

Fonte: Freitas et al. (2001).

Card et al. (1999) sugere o modelo exposto na Figura 2. Os dados brutos passam por uma transformação, onde é gerada uma tabela de dados, após é feito o mapeamento visual, gerando as estruturas visuais onde é feita a transformação para uma visão gerando uma tarefa.

Figura 2: Modelo de referência de visualização de Card et al.

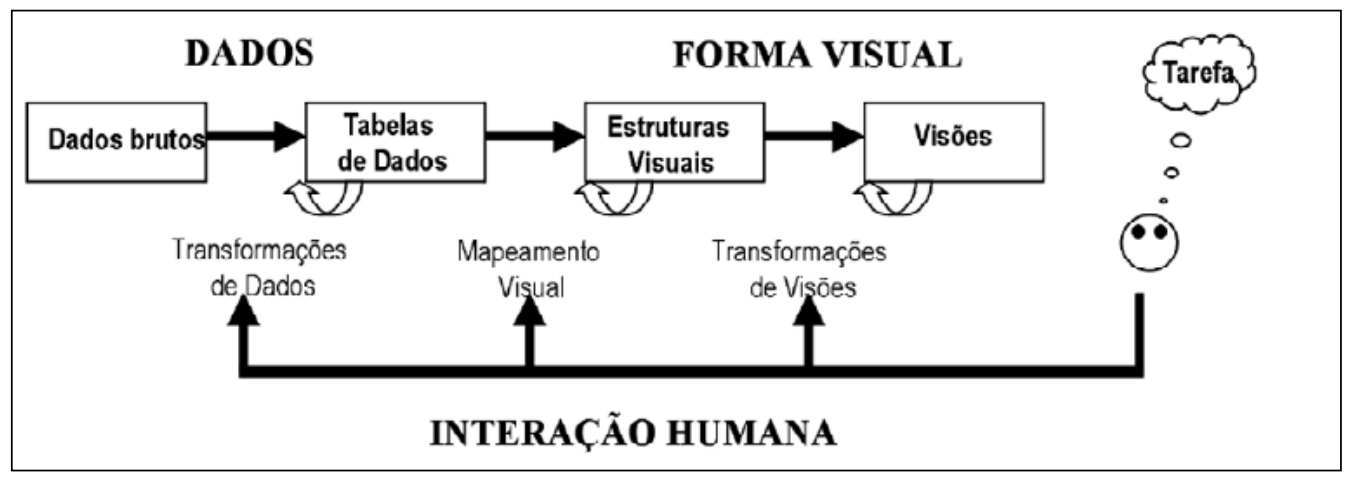

Fonte: Freitas et al. (2001).

Conforme Romani e Rocha (2001) o dado bruto é um dado em um formato muito particular e pode se originar de várias formas, desde textos em livros até formulários de computadores. $\mathrm{O}$ dado bruto é mais facilmente mapeado para formas visuais ao ser transformado em uma relação ou conjunto de relações através de variações de dados que contém valores derivados ou estruturas, sendo que estas relações são denominadas de tuplas, ou seja, uma 
relação ordenada de elementos. Já as tabelas de dados possuem um conceito diferente ao atribuído às tabelas em banco de dados, elas combinam relações com metadados que representam essas relações. Por exemplo, uma tabela de dados para livros poderia conter os livros nas colunas e as variáveis nas linhas, representando as propriedades daquele livro.

De acordo Luzzardi (2003) as estruturas visuais têm por objetivo, de modo geral, apresentar informações adicionais sobre elementos do conjunto de dados através da variação do ponto de observação, manipulação geométrica ou indicação de local ou subconjunto de interesse. Sendo então, estas estruturas visuais exibidas em vistas ou imagens originadas das estruturas mapeadas.

\section{TÉCNICAS DE VISUALIZAÇÃO DE INFORMAÇÕES}

As técnicas de visualização de informações utilizam metáforas ou representações visuais com o objetivo de exibir graficamente dados que normalmente não possuem representação direta, óbvia ou natural. Diferentes autores tentaram criar classificações para auxiliar os usuários na escolha da técnica mais adequada de visualização para enquadrar seus dados. Muitas destas técnicas tiveram como base objetos do mundo real como inspiração para mapear o conjunto de informações. Elas podem utilizar representações visuais 1D, 2D ou 3D (LUZZARDI, 2003).

Conforme Vaz e Carvalho (2004) o principal objetivo na escolha e utilização de uma das técnicas de visualização de informações é a busca pelo maior entendimento do usuário. As informações devem estar claras e simplificadas, não prejudicando ou falhando em uma interpretação, sendo que, em alguns casos uma visualização mal feita pode levar a grandes prejuízos.

Para elaboração deste trabalho foram consideradas como mais relevantes a técnica de Coordenadas Paralelas e a técnica Hierárquica - Treemap. Na técnica de coordenadas paralelas cria-se um eixo para cada um dos atributos, estes eixos são organizados de forma paralela e equidistante, sendo que para cada informação a ser visualizada é marcada uma linha poligonal que cruza os eixos na altura dos valores correspondentes para os atributos (SANTOS et al. 2009). A Figura 3 (a) demonstra um exemplo da representação gráfica desta técnica.

Nas técnicas hierárquicas os dados são particionados nas diferentes dimensões das informações em subespaços de forma hierárquica que podem ser visualizados em duas ou mais dimensões. Uma das mais conhecidas técnicas hierárquicas é a Treemap, onde é ocupada uma área bidimensional com pequenos polígonos, proporcional à relevância para visualização, utilizando retângulos aninhados, características como texturas e cores também podem ser usadas para mostrar informações adicionais na visualização (SANTOS et al. 2009). A Figura 3 (b) demonstra um exemplo da representação gráfica desta técnica. 
Figura 3 (a) e (b): Representação gráfica das técnicas Coordenadas Paralelas e Treemaps

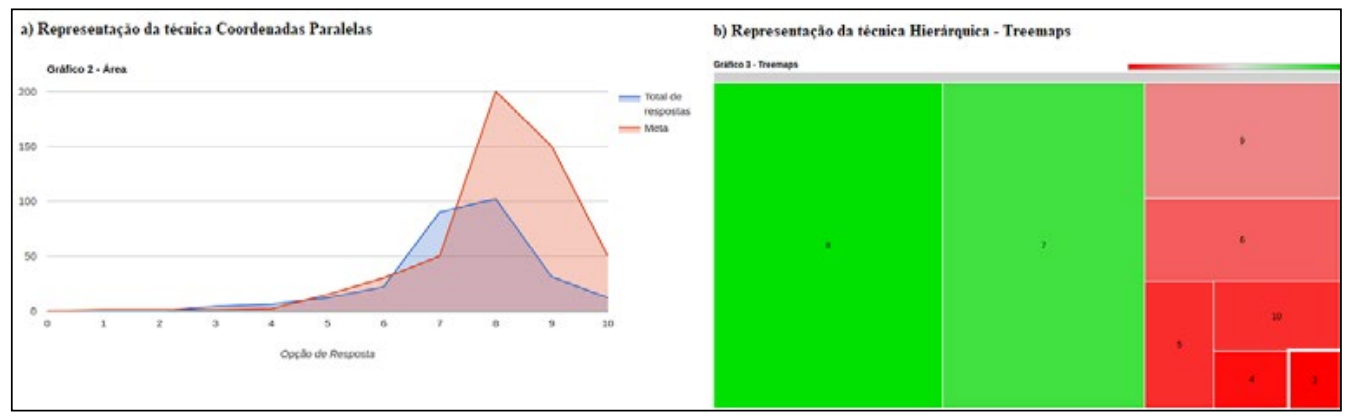

Fonte: elaborado pelo autor (2018).

\section{TRABALHOS RELACIONADOS}

O tema visualização de dados apresenta uma gama diversificada de aplicações e de estudos, sendo que, o que o principal foco está na forma de como representamos as informações para obter um melhor entendimento. Alexandre e Tavares (2007) apresentam em seu artigo os fatores da compreensão visual humana no processo de visualização de dados, eles acreditam que os estudos nesta área precisam evoluir bastante, visto que nos últimos anos, a computação ubíqua se faz cada vez mais presente no nosso cotidiano.

Os autores ainda destacam que a visão é o principal sentido humano com grande capacidade de captar informações, sendo ela o sentido obtido mais rapidamente pelo cérebro. No entanto, eles afirmam que todos os sentidos da percepção humana possuem uma função importante e colaboram na visualização da informação.

Trautenmüller et al. (2014) apresenta em seu artigo um estudo com foco na área médica, devido à necessidade de representar informações extraídas das evoluções clínicas dos pacientes de forma rápida e assertiva, onde propôs ferramentas interativas para trabalhar com os dados, segmentando-os com a finalidade de poder acompanhar e gerar relatórios analíticos das evoluções clínicas dos pacientes oncológicos.

Os autores ressaltam que após o desenvolvimento do protótipo para o tratamento dos dados utilizando técnicas de mineração combinadas com as técnicas de visualização resulta-se em uma grande variedade de visualizações que podem ser utilizadas em inúmeras situações obtendo-se um aproveitamento maior dos dados. Trautenmüller et al. (2014) concluem que a implementação deste visualizador irá auxiliar na tomada de decisões de forma eficiente, pois este apresenta informações que antes não eram percebidas. Constata-se que o estudo apresentado acima vem de encontro com a proposta deste trabalho, 
onde ao utilizar formas alternativas para analisar informações, obtêm-se um apoio nas tomadas de decisões auxiliando no processo de gestão estratégica.

Em seu artigo Pinto et al. (2014) aborda o uso de uma ferramenta web com aplicação de técnicas de visualização de informações para apresentação de dados coletados em uma pesquisa. Os autores salientam a importância da interação nos gráficos aplicando filtros de acordo com as preferências dos usuários, concluindo que ao implementar meios de interação, foi possível selecionar e partilhar a informação.

Luzzardi (2003) apresenta em seu trabalho os critérios de avaliação dos meios de interação, ele relata que a usabilidade de uma técnica de visualização depende de um conjunto de operações para interagir com as informações, onde ao implementar de forma eficiente essas operações os usuários possuem mecanismos adequados de interação para realização de suas tarefas, tanto do ponto de vista de interface gráfica, quanto algoritmo, sendo que a avaliação destes mecanismos é realizada levando em consideração critérios como, facilidade e eficiência de uso, satisfação subjetiva e erros do usuário.

$\mathrm{O}$ autor descreve a filtragem como um dos mecanismos de interação que possibilitam ao usuário realizar operações diretamente sobre os dados, pois ao interagir com a visualização o usuário modifica o contexto global da informação, identificando e eliminando itens sem interesse no momento, assim inicialmente o usuário visualiza uma determinada estrutura e através de sequências dinâmicas de consultas é possível visualizar uma nova estrutura de informações de forma hierárquica e rapidamente localizar uma nova seção com as informações desejadas, característica presente na técnica Treemaps (LUZZARDI, 2003).

A poda é outro meio de interação, onde ao reduzir o número de elementos presentes na visualização o usuário elimina determinada característica especial da representação visual. Outro método de interação é a busca, onde as técnicas devem fornecer meios rápidos e eficazes para encontrar as informações, expansão, é outro mecanismo, onde ao expandir a estrutura é possível exibir uma quantidade maior de informações permitindo uma nova interpretação dos dados. O agrupamento é outro modo citado pelo autor, onde através da formação de grupos as informações são ajustadas no espaço disponível na tela (LUZZARDI, 2003).

\section{METODOLOGIA}

Quanto aos fins a pesquisa é de caráter exploratório e aplicada, segundo Marconi e Lakatos (2010) no tipo de pesquisa exploratório as investigações têm por objetivo a formulação de questões ou formulação de um problema com tripla finalidade: desenvolver hipóteses, aumentar a familiaridade, modificar e clarificar conceitos. 
Para realização do presente trabalho foram utilizados dados gerados através de uma pesquisa de satisfação realizada com duzentos e oitenta consumidores do comércio de Lajeado. Os dados utilizados se encaixam nas classes alfanumérico, numérico e discreto. Segundo Prodanov e Freitas (2013) na pesquisa quantitativa considera-se que tudo pode ser quantificável, ou seja, as opiniões e informações são traduzidas através de números.

Primeiramente foi realizada uma pesquisa bibliográfica com o objetivo de entender acerca do assunto, segundo Gil (2002) a pesquisa bibliográfica se constitui de livros e artigos científicos já elaborados anteriormente, sendo que boa parte dos estudos exploratórios podem ser definidos como pesquisas bibliográficas. De posse dos conceitos teóricos, definiu-se as formas de visualização que seriam utilizadas para então avaliar algumas ferramentas que poderiam auxiliar na implementação do protótipo para apresentação dos resultados. O protótipo foi desenvolvido fazendo uso das técnicas e ferramentas avaliadas com intuito de avaliar sob o ponto de vista da abordagem qualitativa, que conforme Figueiredo e Souza (2011), no método qualitativo as informações fundamentam-se das interações interpessoais e da coparticipação dos informantes.

\section{FERRAMENTA DESENVOLVIDA}

Para desenvolvimento desta ferramenta foi utilizado a biblioteca Google Chart, essa biblioteca é utilizada como apoio para o desenvolvimento de sistemas para Internet. Na sequência serão apresentados detalhes da ferramenta que foi implementada para ser utilizada nas entrevistas com os gestores. A Figura 4 apresenta a tela inicial do sistema com a relação de perguntas que foram utilizadas nas entrevistas. $\mathrm{O}$ sistema desenvolvimento foi executado localmente, não foi disponibilizado na web, devido a isso não foram implementadas tela para login e também não existe controle de permissões. 
Figura 4 - Listagem de Perguntas

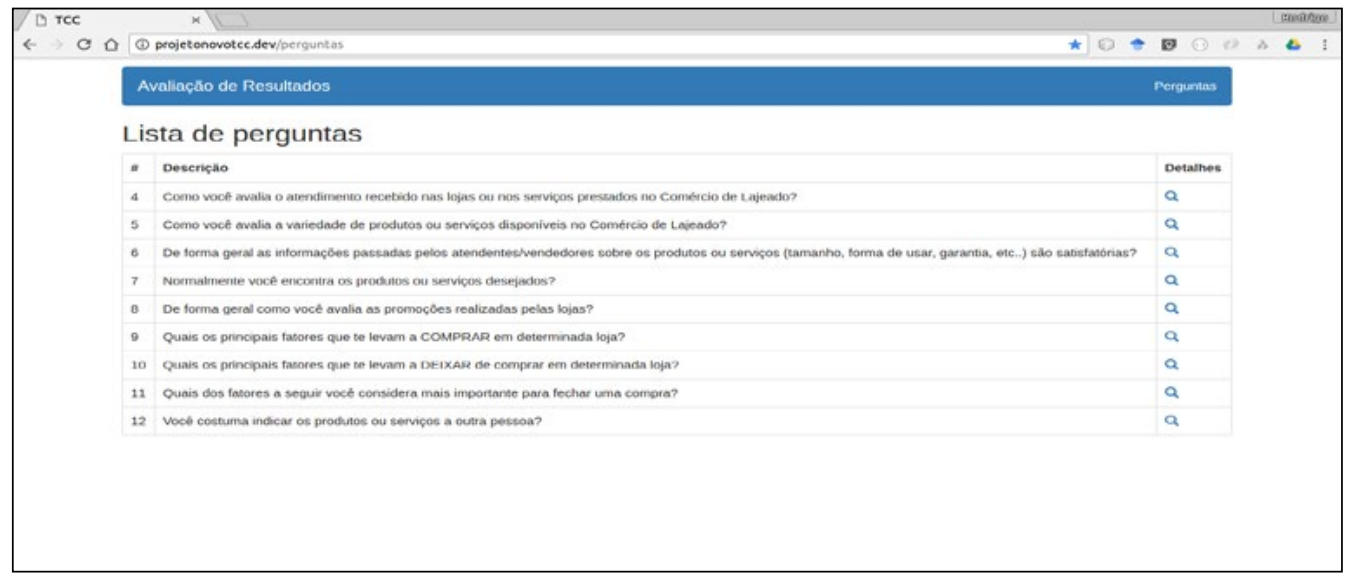

Fonte: elaborado pelo autor (2018).

A Figura 5 apresenta os gráficos utilizados nas entrevistas com os gestores, o primeiro gráfico é o de Barras Verticais, forma de visualização normalmente disponível em sistemas de gestão (ERPs). O segundo é um gráfico de área, formato alternativo para representar a informação, no qual implementa características da técnica de Coordenadas Paralelas. Já o terceiro é o gráfico Treemaps, no qual explora as características dessa técnica hierárquica.

Figura 5 - Gráficos utilizados nas entrevistas

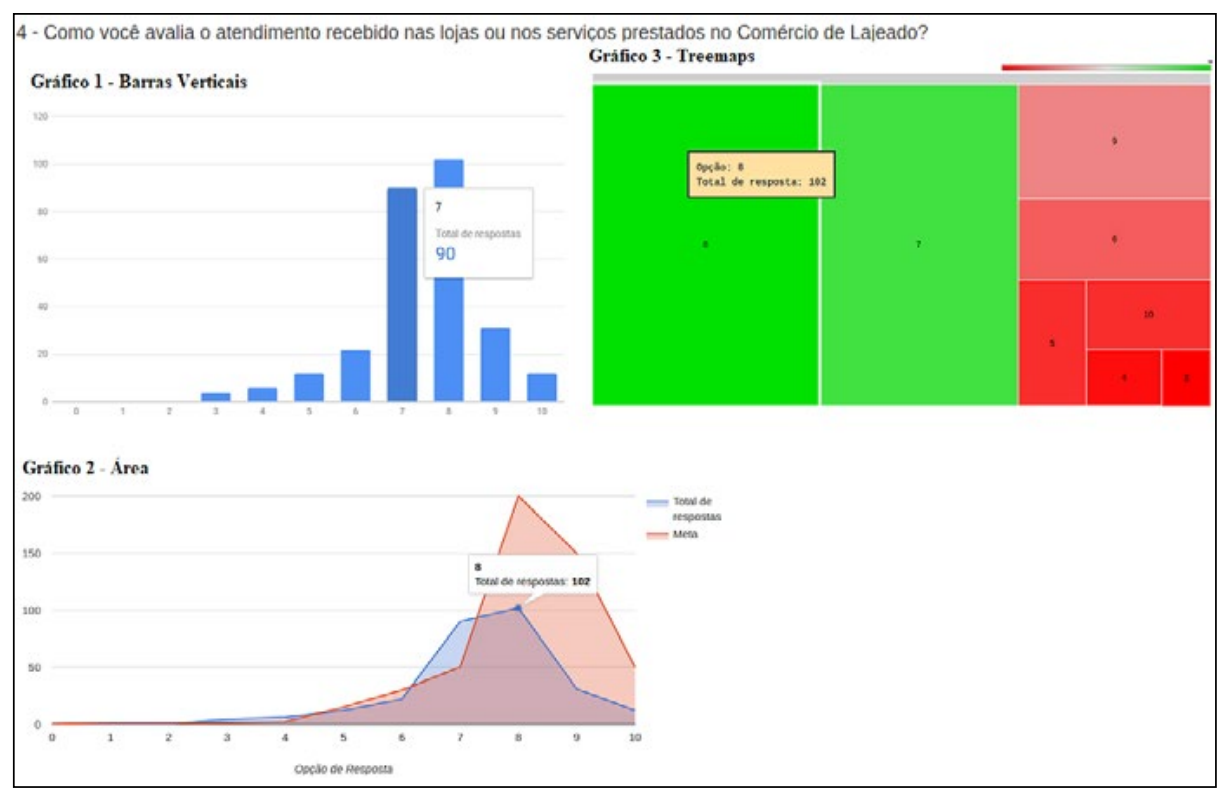

Fonte: elaborado pelo autor (2018). 
A justificativa da escolha destes formatos de representação está exposta na seção (Análise das visualizações). Na sequência serão apresentados os processos para aplicação da pesquisa e análise dos resultados.

\section{APLICAÇÃO DA PESQUISA E ANÁLISE DOS RESULTADOS}

Neste capítulo serão apresentados os dados obtidos na pesquisa de satisfação com os consumidores e também a análise das formas de visualizações desenvolvidas e apresentadas nas entrevistas aos gestores.

\section{APLICAÇÃO DA PESQUISA E COLETA DOS DADOS}

Nessa pesquisa foram coletados duzentos e oitenta questionários com consumidores do comércio de Lajeado, a coleta dos dados aconteceu de forma online, onde foram enviados convites para contatos de aplicativos de mensagens (Facebook Messenger e Whatsapp), com o link para acesso à pesquisa, outro meio de coleta utilizado foi abordagens de forma presencial, disponibilizando uma tablet para os respondentes, para que os mesmos pudessem responder a pesquisa. O questionário contemplou 16 perguntas abertas e fechadas, que teve como objetivo identificar a satisfação dos clientes em relação aos produtos e serviços ofertados no comércio de Lajeado.

\section{ENTREVISTA COM OS GESTORES}

A amostra abrangeu 11 gestores que atuam no comércio de Lajeado nos seguintes segmentos: lojas de vestuário, calçados, utilidades domésticas e construção civil. Os gestores foram entrevistados com o objetivo de analisarem as formas de visualizações implementadas com base nos dados obtidos na pesquisa realizada com os consumidores. No total foram apresentadas nove perguntas, entre elas perguntas relacionadas a qualidade e fatores que determinam a comprar ou não, entre outras.

Após apresentação das nove perguntas foi solicitado aos mesmos que respondessem a um questionário com objetivo de avaliarem as formas de visualizações apresentadas. Os entrevistados foram questionados em relação ao nível de entendimento e quantidade de informações presentes nos gráficos, e quanto ao nível de interação dos mesmos.

\section{CARACTERIZAÇÃO DO PERFIL}

O cargo que os 11 entrevistados exercem nas empresas são de auxiliar administrativo, gerentes e sócios dos estabelecimentos, nos quais estão acostumados trabalhar com informações gerenciais. A Tabela 1 demonstra a frequência que os entrevistados analisam informações gerenciais, onde concluise que a maioria está habituado a analisar essa atividade. 
Tabela 1 - Análise das informações gerenciais

\begin{tabular}{c|c}
\hline Frequência & $\mathbf{N}^{\circ}$ de pessoas \\
\hline Sempre & 6 \\
\hline Quase sempre & 4 \\
\hline Às vezes & 0 \\
\hline Raramente & 1 \\
\hline Nunca & 0 \\
\hline
\end{tabular}

Fonte: Elaborado pelo autor (2017).

Observa-se na Tabela 2 que normalmente as análises realizadas pelos gestores possuem alguma informação representada em gráficos.

Tabela 2 - Frequência de utilização de gráficos nas análises

\begin{tabular}{c|c}
\hline Frequência & $\mathbf{N}^{\circ}$ de pessoas \\
\hline Sempre & 2 \\
\hline Quase sempre & 1 \\
\hline Às vezes & 4 \\
\hline Raramente & 2 \\
\hline Nunca & 2 \\
\hline Não sei opinar & 0 \\
\hline
\end{tabular}

Fonte: Elaborado pelo autor (2017).

Quando questionados referente a qual tipo de gráfico estão acostumados a utilizar nestas análises e em situações como: reuniões, apresentações, relatórios, entre outros, os mesmos responderam que na maioria das vezes costumam utilizar gráficos de barras ou pizza.

\section{ANÁLISE DAS VISUALIZAÇÕES}

Nas entrevistas com os gestores foram apresentados os dados da pesquisa de satisfação em três formatos de visualização distintos, buscando identificar a impressão dos mesmos em relação ao nível de entendimento, a quantidade de informações contidas em cada um dos gráficos, e também o nível de interação. Após a entrevista os gestores atribuíram notas a estes itens. O primeiro gráfico foi um tradicional, normalmente presente em sistemas ERP's, gráfico de Barras Verticais, o segundo foi um gráfico de Área e o terceiro o gráfico Treemaps.

A escolha pela representação através do gráfico de Barras Verticais foi devido ao mesmo ser uma forma tradicional de representar informações, visto que, o objetivo das entrevistas era comparar as visualizações alternativas com a forma tradicional. Como uma das formas alternativas optou-se pelo 
gráfico de Área, pois o mesmo possibilita representar características da técnica de coordenadas paralelas. A outra forma alternativa escolhida foi o gráfico Treemaps devido ao fato deste explorar as características da técnica hierárquica - Treemap. Um dos fatores determinantes para estas escolhas foi a caracterização dos dados que possibilitam a representação da mesma informação nos três formatos.

Para apresentação dos dados foi agendado um horário com os gestores, sendo que a entrevista foi conduzida em forma de apresentação, onde além dos entrevistados avaliarem as visualizações as mesmas foram explicadas.

Os entrevistados analisaram os três modelos de gráficos em nove perguntas quantitativas da pesquisa realizada com os consumidores do comércio de Lajeado. Primeiramente foi selecionada uma pergunta, após o resultado desta pergunta foi analisado nos três formatos de visualização, sendo que este processo foi repetido para as nove perguntas selecionadas.

O primeiro gráfico analisado pelos gestores foi o de Barras Verticais, forma tradicional de visualização, no qual apresentava o total de respostas obtidas para a questão. Este gráfico permitia ao usuário interagir com a informação, onde ao passar o mouse sobre a barra era possível identificar a opção selecionada e o total de respostas obtidos para a questão.

O segundo gráfico demonstrava a mesma informação do formato anterior, porém utilizando um gráfico de Área, onde além de representar o total de respostas era possível identificar uma meta pré-estabelecida para opção de resposta. Sendo que a interação disponível para este formato se assemelha a anterior, onde ao passar o mouse sobre a linha era possível identificar a opção selecionada e o total de respostas obtidos para a questão ou a meta estipulada para a opção.

O terceiro gráfico utilizado exibia a mesma informações dos anteriores utilizando o gráfico Treemaps, onde cada opção de resposta era apresentada nos retângulos distribuídas de forma proporcional ao número de respostas recebidas para a opção. Neste formato a cor também destacava os espaços ocupados pelas opções de resposta, sendo que, a opção que recebeu mais respostas era colorida em uma escala variável entre as cores verde e vermelho.

Uma das possibilidades de interação disponíveis nesta visualização, é que ao passar o mouse em uma das alternativas é apresentado a opção selecionada e o total de respostas obtidos na mesma. Além disso é possível navegar entre os diferentes níveis pré-configurados, ou seja, ao clicar com o botão esquerdo do mouse em uma das opções obtém-se mais detalhes em relação a resposta selecionada, apresentando o valor de forma proporcional de acordo com a nova categoria, para voltar ao nível anterior utiliza-se o botão direito do mouse, portanto, a cada clique sobre uma área, pode-se ver um nível mais específico. A Figura 6 demonstra um exemplo desta navegação entre os níveis. 
Figura 6 - Gráfico Treemaps

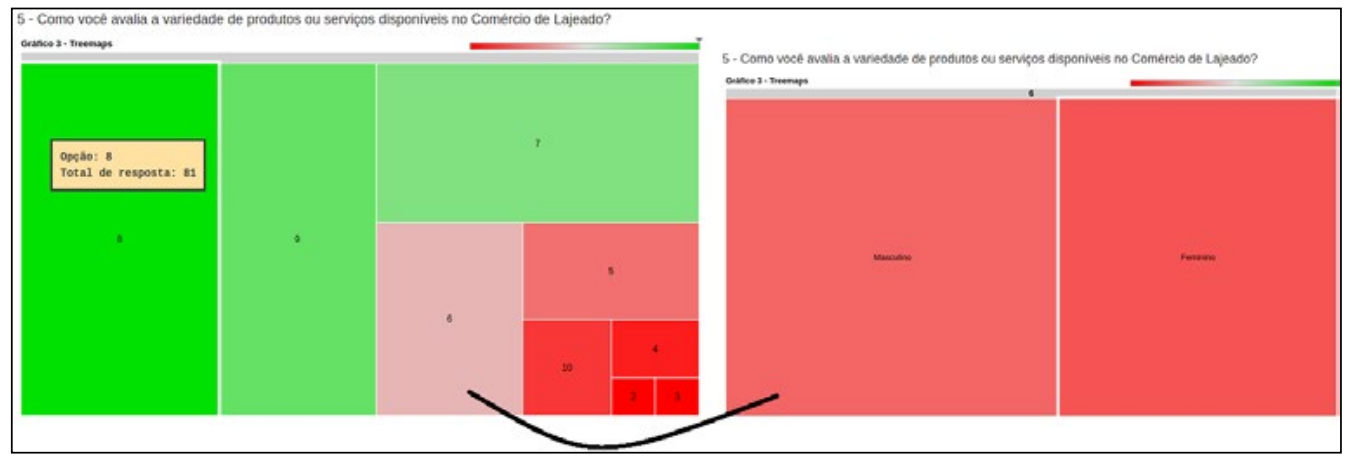

Fonte: Elaborado pelo autor (2018).

Os gestores tinham a tarefa de ver as informações gerenciais em formas distintas, por meio do gráfico tradicional (Barras Verticais) e duas formas alternativas (Gráfico de Área e Treemaps), após foi solicitado para que os mesmos realizassem a avaliação em relação ao entendimento das informações contidas nas representações. Os resultados das avaliações serão apresentados no capítulo seguinte.

\section{ANÁLISE DOS GESTORES EM RELAÇÃO ÀS FORMAS DE VISUALIZAÇÃO}

Após serem apresentadas as formas de visualizações aos gestores, foi solicitado aos mesmos que fizessem uma avaliação referente a algumas características, os resultados desta análise serão apresentados a seguir.

A Tabela 3 apresenta o resultado da avaliação dos gestores quanto ao nível de entendimento das informações contidas no gráfico 2 (gráfico de Área) e no gráfico 3 (gráfico Treemaps), forma alternativa de representar a informação, em relação ao gráfico 1 (gráfico de Barras Verticais), forma tradicional.

Tabela 3 - Nível de entendimento das informações

\begin{tabular}{c|c|c}
\hline & $\begin{array}{c}\text { Gráfico 2 em relação } \\
\text { ao gráfico 1 }\end{array}$ & $\begin{array}{c}\text { Gráfico 3 em relação ao } \\
\text { gráfico 1 }\end{array}$ \\
\hline A informação está mais clara & 4 & 10 \\
\hline Não percebi diferença & 0 & 1 \\
\hline A informação ficou mais confusa & 2 & 0 \\
\hline
\end{tabular}

Fonte: Elaborado pelo autor (2017).

Observa-se que para maioria dos entrevistados o gráfico 3 (Treemaps) possui um nível de entendimento superior em relação aos demais. Essa 
pergunta possibilitou que o entrevistado deixasse comentários, um deles deixou um comentário dizendo que nos gráficos 1 (Barras Verticais) e gráfico 3 (Treemaps) a informação está mais clara e outro que após a explicação há mais entendimento.

A Tabela 4 apresenta o resultado da avaliação dos gestores quanto a quantidade de informações contidas nos gráficos 2 (gráfico de Área) e 3 (gráfico Treemaps) em relação ao gráfico 1 (Barras Verticais).

Tabela 4 - Quantidade de informações

\begin{tabular}{c|c|c}
\hline & $\begin{array}{c}\text { Gráfico 2 em relação } \\
\text { ao gráfico 1 }\end{array}$ & $\begin{array}{c}\text { Gráfico 3 em relação } \\
\text { ao gráfico 1 }\end{array}$ \\
\hline Apresentou mais informações & 7 & 9 \\
\hline $\begin{array}{c}\text { Os gráficos possuem o mesmo número } \\
\text { de informação }\end{array}$ & 1 & 1 \\
\hline $\begin{array}{c}\text { Não compreendi as informações } \\
\text { apresentadas nos gráficos 2 e 3 }\end{array}$ & 0 & 0 \\
\hline
\end{tabular}

Fonte: Elaborado pelo autor (2017).

Nota-se que para grande maioria dos entrevistados ficou claro que os gráficos 2 e 3 apresentam um número maior de informações. Um dos entrevistados deixou um comentário em relação a este item: "o gráfico 2 mostra um comparativo com o que era esperado inicialmente, mas o três é muito bom pois pode ser aberto ainda mais definindo por gênero, idade, entre outros". Este comentário ressalta a importância de o gráfico trazer um número maior de informações, visto que, a informação é fundamental para o processo de gestão estratégica.

A Tabela 5 apresenta a avaliação dos gestores quanto a interação contida nos gráficos 2 e 3 em relação ao gráfico 1 .

Tabela 5 - Interação

\begin{tabular}{c|c|c}
\hline & $\begin{array}{c}\text { Gráfico 2 em } \\
\text { relação ao gráfico 1 }\end{array}$ & $\begin{array}{c}\text { Gráfico 3 em relação } \\
\text { ao gráfico 1 }\end{array}$ \\
\hline $\begin{array}{c}\text { Muito boa, os gráficos apresentam um } \\
\text { bom nível de interação }\end{array}$ & 7 & 11 \\
\hline Regular, quase não notei diferença & 2 & 0 \\
\hline Ruim & 0 & 0 \\
\hline
\end{tabular}

Fonte: Elaborado pelo autor (2017).

Observa-se que 100\% dos entrevistados assinalaram que o gráfico 3 (Treemaps) apresentou um nível maior de interação, este resultado era esperado devido à possibilidade de navegar entre os níveis e detalhar a informação disponível nesta visualização. O Gráfico 2 (Área) também apresentou um 
percentual alto em relação a este item, resultado não esperado, visto que a interação disponível é a mesma do gráfico 1 (Barras Verticais).

\section{ANÁLISE DOS GESTORES EM RELAÇÃO À PESQUISA}

Ao serem questionados se passariam a utilizar as visualizações propostas nos gráficos 2 (Área) e gráfico 3 (Treemaps) oito gestores assinalaram que sim, na maioria das vezes passariam a utilizar, 2 que sempre utilizariam, e um que talvez utilizaria, este resultado é representado na Figura 7 (a). Os entrevistados também foram questionados em relação a preferência para analisar informações entre o gráfico 1 (Barras Verticais), gráfico 2 (Área) e gráfico 3 (Treemaps). O resultado deste questionamento é apresentado na Figura 7 (b).

Figura 7 (a) e (b) - Utilização e preferência das visualizações

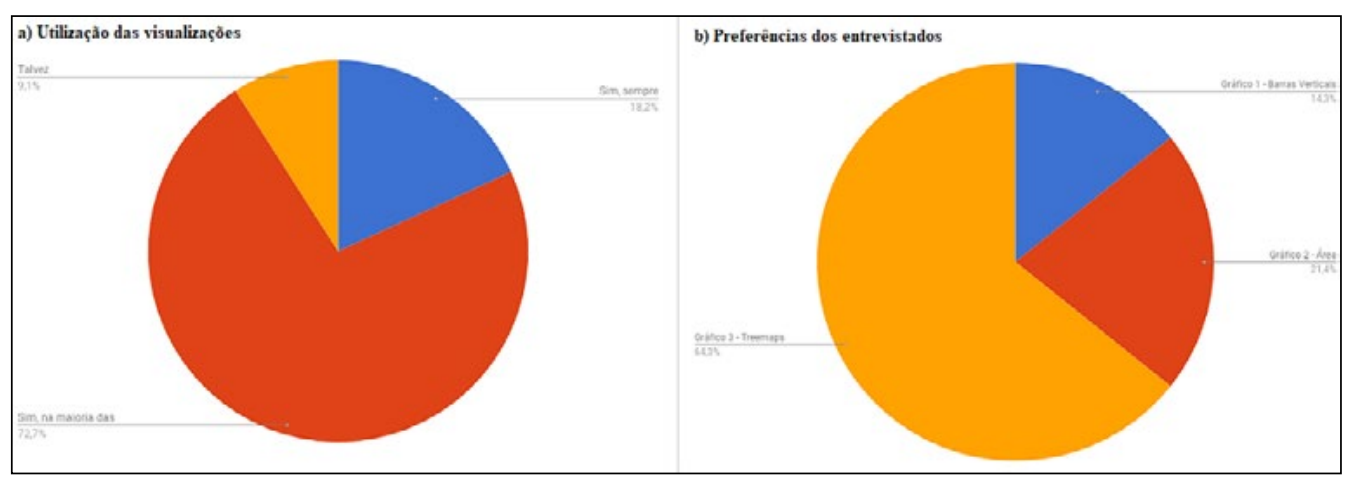

Fonte: Elaborado pelo autor (2018).

Nota-se que $72,7 \%$ dos gestores passariam a utilizar na maioria das vezes as visualizações propostas nos gráficos 2 (Área) e 3 (Treemaps) como forma alternativa de representar as informações em suas análises gerenciais. Já em relação a preferência observa-se nos resultados das entrevistas que 64,3\% dos entrevistados possuem preferência pelo gráfico 3 (Treemaps) para analisar as informações em relação aos modelos apresentados.

Ao serem questionados quanto a importância em pesquisar a forma de visualizar as informações $100 \%$ dos entrevistados disseram que a pesquisa se mostrou relevante, ou seja, com isso fica evidente a importância de estudos nesta área. Ao final foi solicitado para que os mesmos atribuíssem uma nota de 0 a 10 para as formas de visualização apresentadas, sete atribuíram nota 10 , três atribuíram nota 9 e um nota 8. Levando em consideração as notas atribuídas pelos gestores constata-se que a pesquisa se mostrou relevante. 


\section{CONSIDERAÇÕES FINAIS}

A pesquisa realizada buscou identificar como as técnicas de visualização podem ser utilizadas para apresentação da mesma informação de formas distintas, identificando se estas representações são eficazes na transmissão das informações e como podem auxiliar na gestão estratégica.

Os resultados desta pesquisa possibilitam identificar na visão dos gestores que a utilização de formas alternativas de visualizar as informações pode ser eficaz no processo de análise da informação. Os dados sinalizam que grande parte dos entrevistados passariam a utilizar as formas de visualizações propostas como alternativa ao formato tradicional.

Os resultados apontam que nas análises realizadas pelos gestores normalmente são utilizados gráficos tradicionais (pizza e barras), porém ao serem apresentadas formas alternativas de representar estas informações as mesmas foram compreendidas e se mostraram eficazes na representação da informação, visto que, em algumas das visualizações o número de informação foi maior e também possibilitou um nível maior de interação. Detectou-se que dentre as opções de visualizações apresentadas no trabalho o gráfico Treemaps foi a preferência de $64,3 \%$ dos entrevistados.

Conclui-se que a maioria dos gestores estão habituados a analisar informações gerenciais e que para os mesmos a pesquisa se mostrou relevante, visto que, as notas atribuídas as formas de visualizações apresentadas ficaram entre 8 e 10 e podem auxiliar no processo de gestão de forma estratégica.

Salienta-se ainda que houve limitadores para o presente trabalho, sendo um deles o curto prazo, delimitando o método qualitativo e quantitativo. $\mathrm{Na}$ pesquisa qualitativa, por exemplo, poderia abranger mais gestores, pois desta forma seria obtido um número maior de feedbacks em torno das formas de representar as informações. Recomenda-se, para futuros trabalhos, que outros acadêmicos possam realizar pesquisas abrangendo uma amostra maior de formas de visualizar as informações e com outros formatos de representação, visto que o trabalho confirma que os gestores utilizariam formas alternativas no processo de gestão.

\section{REFERÊNCIAS}

ALEXANDRE, Dulclerci Sternadt; TAVARES, João Manuel R. S. Factores da Percepção Visual Humana na Visualização de Dados. Disponível em: <http:// ddimmrg.xpg.uol.com.br/fatores_da_percepcao_visual_humana_na_visualizacao_ de_dados.pdf $>$. Acesso em: 19 de novembro de 2017.

BARBOSA, Paulo Eduardo de Castro Teles. Uso de técnicas de visualização de informação para o estudo de tráfegos de gerenciamento de redes. Disponível em: <http:/ /hdl.handle.net/10183/28740>. Acesso em: 19 de novembro de 2017. 
BRUM, Analisa de Medeiros. Endomarketing como estratégia de gestão: Encante seu cliente interno. Porto Alegre: L\&PM, 1998.

ESTIVALET, Luiz Fernando. O Uso de Ícones na Visualização de Informações.

Disponível em: <http:/ / hdl.handle.net/10183/1629>. Acesso em: 31 de maio de 2017.

FREITAS, Carla Maria Dal Sasso; et al. Introdução à Visualização de Informações. Disponível em: <http://hdl.handle.net/10183/19398>. Acesso em: 09 de maio de 2017.

FIGUEIREDO, Antônio Macena de; SOUZA, Soraia Riva Goudinho de. Como elaborar projetos, monografias, dissertações e teses: da redação científica à apresentação do texto final. 4. Ed. Rio de Janeiro: Lumen Juris, 2011.

GIL, Antônio Carlos. Como Elaborar Projetos de Pesquisa. 4. Ed. São Paulo, Brasil, 2002.

LAKATOS, Eva Maria; MARCONI, Marina de Andrade. Fundamentos de metodologia científica. 7. ed. São Paulo: Atlas, 2010.

LUZZARDI, Paulo Roberto Gomes. Critérios de avaliação de técnicas de visualização de informações. Disponível em: <http:/ / hdl.handle.net/10183/4764>. Acesso em: 23 de maio de 2017.

MAZZA, Riccardo. Introduction to Information Visualization. Springer, 2009.

MICHAELIS. Dicionário de Português Online. Disponível em: <http:/ / michaelis.uol. com.br/moderno-portugues/busca/portugues-brasileiro/visualiza ção $>$. Acesso em: 27 de fevereiro de 2018.

NASCIMENTO, Hugo A. D.; FERREIRA, Cristiane B. R. Visualização de Informações: Uma Abordagem Prática. Disponível em: <https: / /www.researchgate. net/profile/Hugo_Nascimento/publication/267403645_Visualizao_de_Informaes Uma_Abordagem_Prtica/links/5510a6940cf2ba84483f9704.pdf>. Acesso em: 10 de maio de 2017.

PRODANOV, Cleber Cristiano; FREITAS, Ernani Cesar. Metodologia do trabalho Científico: Métodos Técnicas da Pesquisa do Trabalho Acadêmico. 2. Ed. Novo Hamburgo - Rio Grande do Sul. 2013.

PINTO, Marta et al. 2014. U-TRACER: uma ferramenta de visualização da informação sobre o uso das Tecnologias da Comunicação no Ensino Superior Público Português. Disponível em: <http:/ / revistas.ua.pt/index.php/ID/article/ view/2668/2523>. Acesso em: 20 de novembro de 2017.

ROMANI, Luciana Alvim Santos; ROCHA, Heloísa Vieira da. O uso de técnicas de Visualização de informação como subsidio à formação de comunidades de aprendizagem em EaD. Disponível em: <http:/ / www.inf.ufsc.br/ willrich/ IHC2001/IHC2001.pdf>. Acesso em: 12 de maio de 2017. 
SANTOS, Rafael et al. 2009. Técnicas de Visualização de Dados aplicadas à Segurança da Informação. Disponível em: <http:/ / www.lac.inpe.br/ rafael.santos/Docs/ SBSEG/2009/sbseg2009.pdf>. Acesso em: 06 de novembro de 2017.

TRAUTENMÜLLER, Patrícia et al. 2014. Ambiente de Visualização de Informações para Acompanhamento da Evolução Clínica de Pacientes Oncológicos. Disponível em: <https://www.researchgate.net/publication/242087064_Ambiente_de_

Visualizacao_de_Informacoes_para_Acompanhamento_da_Evolucao_Clinica_de_ Pacientes_Oncologicos>. Acesso em: 10 de novembro de 2017.

VAZ, Fernando Rosa; CARVALHO, Cedric Luiz de. Visualização de Informações. Disponível em: <http:/ / www.portal.inf.ufg.br/sites/default/files/uploads / relatorios-tecnicos/RT-INF_003-04.pdf >. Acesso em: 18 de novembro de 2017. 